\title{
Correlation of clinical staging and MRI staging for cervical cancer
}

\author{
Supajit Nawapun ${ }^{1}$ (D), Chalida Aphinives ${ }^{1 *}$, Wiranya Srisitthiprapha ${ }^{1}$ (D), Komsan Thamronganantasakul ${ }^{1}$ (D) and \\ Amornrat Temtanakitpaisan ${ }^{2}$ (B)
}

\begin{abstract}
Background: Cervical cancer is a major public health problem for women. Accurate staging may lead to proper management of cervical cancer. We retrospectively reviewed all patients with cervical cancer who underwent pretreatment MRI between January 2009 and December 2018 and analyzed the correlation between the clinical staging and MRI staging.

Results: Correlation of overall clinical and MRI staging by percent agreement is moderate (73.9\%), but the kappa coefficient showed a slight correlation. The correlation of clinical and MRI findings in the vaginal invasion, pelvic sidewall invasion, adjacent pelvic organ invasion, and spreading to distant organ also showed moderate-to-strong correlation by percent agreement (ranging from 67.6 to 91.9\%) but slight correlation between clinical and MRI examinations by kappa or weighted kappa coefficient $\left(K=0.000-0.128^{\mathrm{w}}\right)$.

Conclusion: In patients with cervical cancer, pretreatment MRI provides higher spatial soft tissue resolution which can define pelvic tumor extent, including a more accurate assessment of tumor size (due to multiplanar evaluation), parametrial invasion, pelvic sidewall invasion, and adjacent pelvic organ invasion. This could potentially lead to a reduction in staging morbidity by invasive investigation such as cystoscopy and proctoscopy.
\end{abstract}

Keywords: Clinical staging, MRI staging, Cervical cancer, CA cervix

\section{Background}

According to the GLOBOCAN publication in 2020, cervical cancer is ranked as the fifth most common female cancer (16.4 per 100,000), or the third most common in Thailand with the estimated number of approximately 9158 (9.4\% of all female cancer patients) [1].

The treatment of choice for cervical cancer is divided into two main strategies depending on the clinical staging based on the International Federation of Gynecology and Obstetrics (FIGO) classification system [2].

1) Radical surgery (including trachelectomy or radical hysterectomy) for early-stage disease (FIGO stage IA, IB1, and IIA)

\footnotetext{
* Correspondence: chalida.aphinives@gmail.com

${ }^{1}$ Department of Radiology, Faculty of Medicine, Khon Kaen University, Khon Kaen, Thailand

Full list of author information is available at the end of the article
}

2) Primary radiotherapy with concurrent chemotherapy for patients with bulky tumor (FIGO stage IB2/IIA2) or locally advanced disease (FIGO stage IIB or greater)

The FIGO staging is determined by pelvic examination, bladder cystoscopy, proctoscopy, and colposcopy in combination with imaging (including chest and skeletal radiography, intravenous pyelography, and barium enema). However, staging according to the old system (i.e., FIGO cervical cancer staging systems from 1999, 2009 , and 2014) was inaccurate, with $20-40 \%$ of stages IB-IIIB cancer being under-staged and up to $64 \%$ of stage IIIB cancer being over-staged [3]. Clinical assessment based on the old FIGO system also has limitations to evaluate the actual tumor size, adjacent organ involvement, and lymphadenopathy [4].

\section{Springer Open}

(c) The Author(s). 2021 Open Access This article is licensed under a Creative Commons Attribution 4.0 International License, which permits use, sharing, adaptation, distribution and reproduction in any medium or format, as long as you give appropriate credit to the original author(s) and the source, provide a link to the Creative Commons licence, and indicate if changes were made. The images or other third party material in this article are included in the article's Creative Commons licence, unless indicated otherwise in a credit line to the material. If material is not included in the article's Creative Commons licence and your intended use is not permitted by statutory regulation or exceeds the permitted use, you will need to obtain permission directly from the copyright holder. To view a copy of this licence, visit http://creativecommons.org/licenses/by/4.0/. 
Magnetic resonance imaging (MRI) is a non-invasive investigation that can provide a more accurate estimation of tumor size, parametrial and pelvic sidewall invasion, as well as pelvic and abdominal lymphadenopathy which are all important deterministic for the accurate staging of cervical cancer for prognosis and treatment planning. Furthermore, the use of MRI can avoid using unnecessary invasive investigations such as cystoscopy, proctoscopy, and intravenous pyelography [4].

This study is, therefore, aimed to compare and analyze the correlation between clinical and MRI findings and staging of cervical cancer.

\section{Methods}

\section{Study design and population}

This retrospective study included 37 patients with histologically confirmed cervical cancer in the gynecology tumor clinic. The ages of patients ranged from 33 to 74 years old, and all of them underwent assessment of clinical staging according to the FIGO guideline and pretreatment MRI for lower abdomen in our institute from January 2009 to December 2018. This study was approved by the Ethics Committee for Human Research based on the Declaration of Helsinki and the ICH Good Clinical Practice Guidelines.

\section{Inclusion criteria}

All patients with histological confirmation of cervical cancer in the gynecology tumor clinic, from January 2009 to December 2018 and underwent pretreatment MRI in our institute.

\section{Exclusion criteria}

1. Patient with cervical cancer without pretreatment MRI evaluation.

2. The patient underwent previous cervical cancer treatment such as previous surgery (except for tissue diagnosis), previous chemotherapy, or radiation.

\section{Clinical staging}

The clinical FIGO staging information (based on both 2009 and 2018 versions of FIGO staging) of the cervical cancer patients are retrospectively retrieved from the medical records in the Gynecology Tumor Clinic by 1 oncology gynecologist and 1 radiation oncologist who has more than 5 years of experience. The patients with clinical FIGO staging based on 2009 FIGO were restaged according to 2018 FIGO to standardize the clinical staging.

We recorded general information of the patients such as age at diagnosis of cervical cancer, underlying diseases, and histological type.

Clinical staging assessments followed the 2018 FIGO guideline with diagnostic biopsy; pelvic examination; chest radiography; proctoscopy; bladder cystoscopy; intravenous pyelography; or kidney, ureter, and bladder ultrasound. The records include tumor size, vaginal wall invasion, parametrial invasion, pelvic sidewall invasion, hydronephrosis or nonfunctioning kidney, adjacent organ involvement (bladder or rectum invasion), and distant organ metastasis.

\section{Pretreatment MRI staging}

We retrospectively performed data collection of the cervical cancer patients with pretreatment MRI (from January 2009 to December 2018). The MRI examination records were read in consensus by two radiologists with more than 5 years of experience in female pelvic imaging. The radiologists were aware of the biopsy-proven diagnosis of cervical cancer but were blinded to the patient's identity, the results of physical examination, and clinical staging. The following findings were recorded by radiologists $[4,5]$.

- Tumor size (in the longest dimension)

- Vaginal wall invasion (disruption of low-signal intensity vaginal wall) as shown in Fig. 1

- Parametrial invasion (disruption of the low-intensity cervical stromal rim, nodularity of parametrial and/ or tumor extending to parametrium) as shown in Fig. 2

- Pelvic sidewall invasion (extension of tumor within 2 $\mathrm{mm}$ of pelvic sidewall, or involvement of internal obturator, piriformis or levator ani muscles with or without dilated ureter) as shown in Fig. 3

- Hydroureter and hydronephrosis ***Hydronephrosis is recorded from additional upper abdominal CT or bladder ultrasound because the small field of view (FOV) of lower abdominal MRI does not include adequate FOV of both kidneys ${ }^{* * *}$

- Lymphadenopathy is based on morphology such as indistinct margin, heterogeneous enhancement or round shape and/or $\geq 0.8 \mathrm{~cm}$ in short-axis size (Fig. 4).

- Adjacent pelvic organ involvement; bladder/bowel wall involvement (Fig. 5), tumor infiltration into bladder/bowel wall mucosa (Fig. 6)

- Distant organ metastasis (interpreted by distant organ involvement such as visible metastasis to bone in the pelvic region, ovary, urethra, or vaginal labia or interpreted by pulmonary metastasis in chest radiography)

The final MRI staging was made based on the 2018 FIGO guideline.

\section{Statistical analysis}

The correlation between clinical and MRI stagings was demonstrated using the Kappa coefficient and weighted Kappa with percent agreement. 


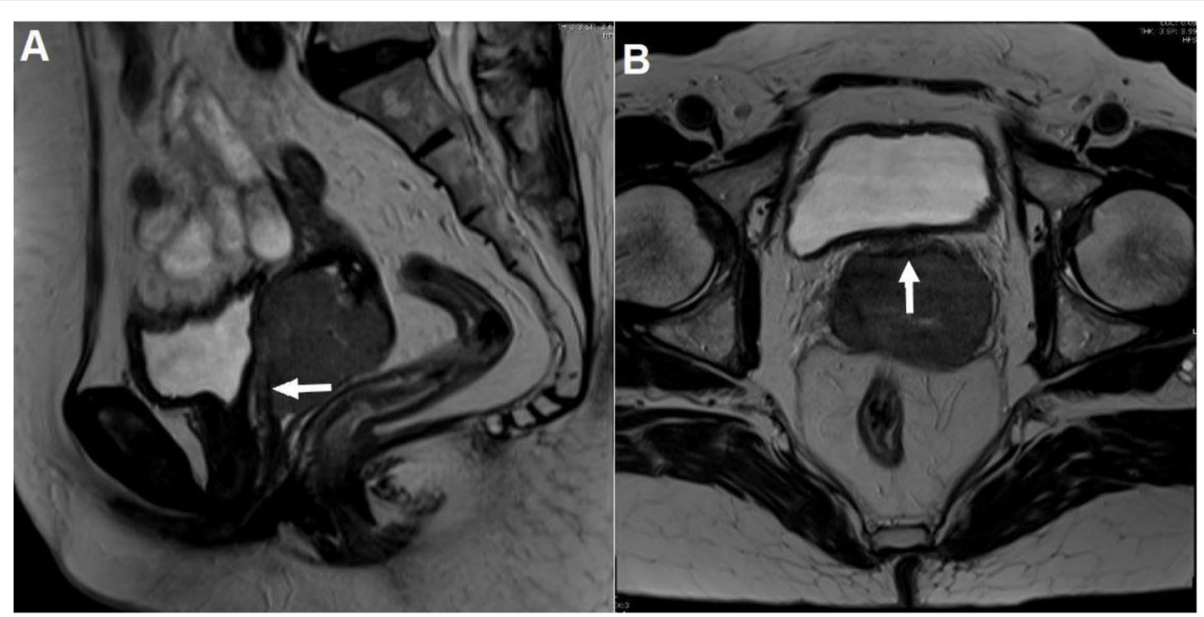

Fig. 1 T2W MRI showed disrupted hypointense vaginal wall (arrows) indicating vaginal invasion: A Sagittal view, B Axial view

Correlation of tumor sizes between clinical and MRI stagings was analyzed using interclass correlation coefficient.

This study was approved by the Institution Ethics Committee for Human Research based on the Declaration of Helsinki and the ICH Good Clinical Practice Guidelines.

\section{Results}

The median age was $54.1 \pm 9.6$ years. All cervical cancers $(37,100 \%)$ were squamous cell carcinoma, and large cell non-keratinizing type was the most common histological type $(17,46.0 \%)$ (Table 1). All patients were clinically staged as IIIB, while MRI staging showed multiple stages as follows: 4 patients (10.8\%) of stage IIB, 1

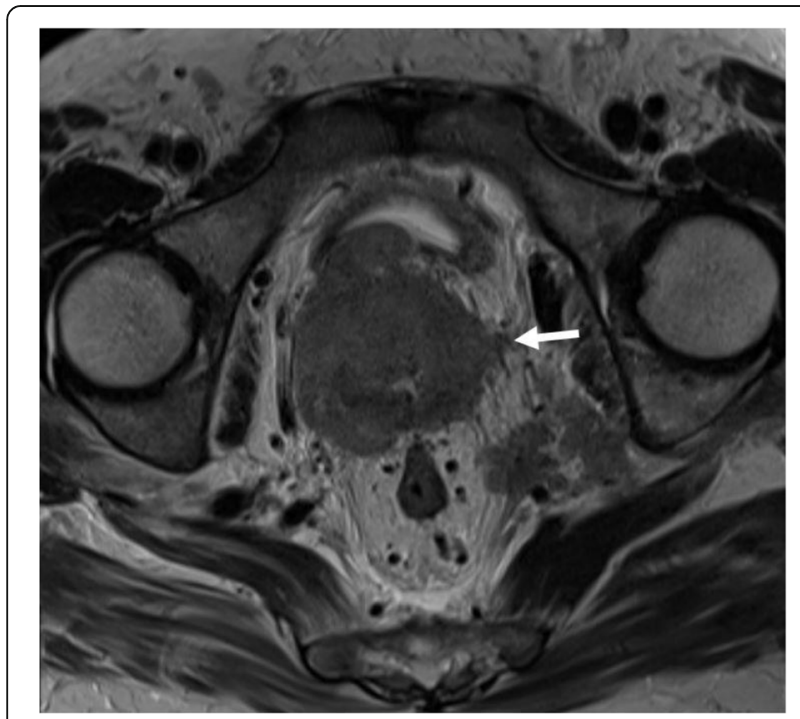

Fig. 2 Axial T2W MRI showed irregular tumor signal extending to parametrium (parametrial invasion) (arrow) patient $(2.7 \%)$ of stage IIIA, 4 patients $(10.8 \%)$ of stage IIIB, 18 patients (48.7\%) of stage IIIC1, 2 patients $(5.4 \%)$ of stage IIIC2, 5 patients (13.5\%) of stage IVA, and 3 patients $(8.1 \%)$ of stage IVB.

Overall clinical and MRI stagings showed a strong correlation with $78.4 \%$ agreement. Clinical and MRI evaluation showed the correlation in vaginal invasion $(77.0 \%$ agreement, $\left.\mathrm{K}=0.128^{\mathrm{w}}\right)$, pelvic sidewall invasion $(67.6 \%$ agreement, $\mathrm{K}=0.098)$, adjacent pelvic organ invasion (78.4\% agreement, $\mathrm{K}=0.000$ ), and spreading to distant organ (91.9\% agreement, $\mathrm{K}=0.000$ ) (Table 2 ).

According to kappa coefficient, clinical and MRI evaluation for hydronephrosis showed a statistically significant substantial correlation $(\mathrm{K}=0.749, \mathrm{P}$ value < $0.001)$.

The interclass correlation coefficient for tumor sizes determined by clinical and MRI evaluations showed

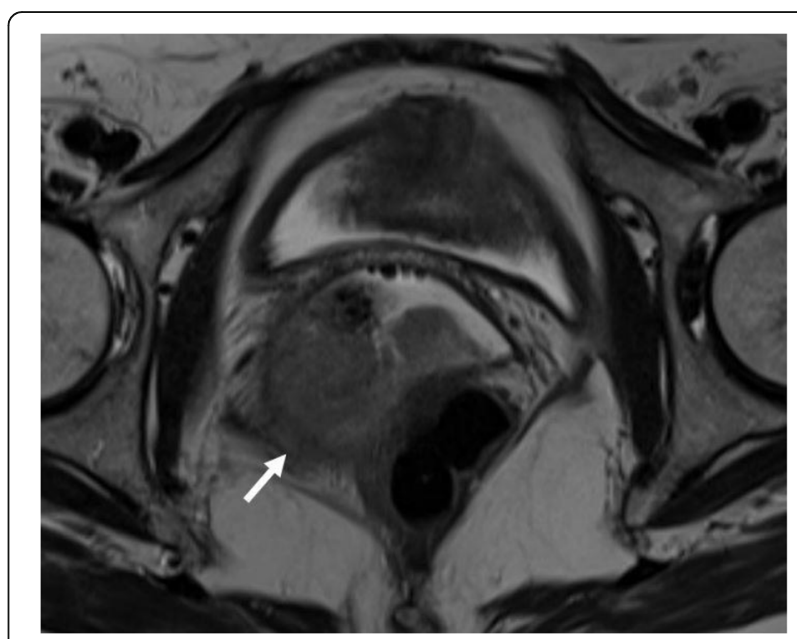

Fig. 3 Axial T2W MRI showed tumor involving right levator ani muscles (pelvic side wall invasion) (arrow) 


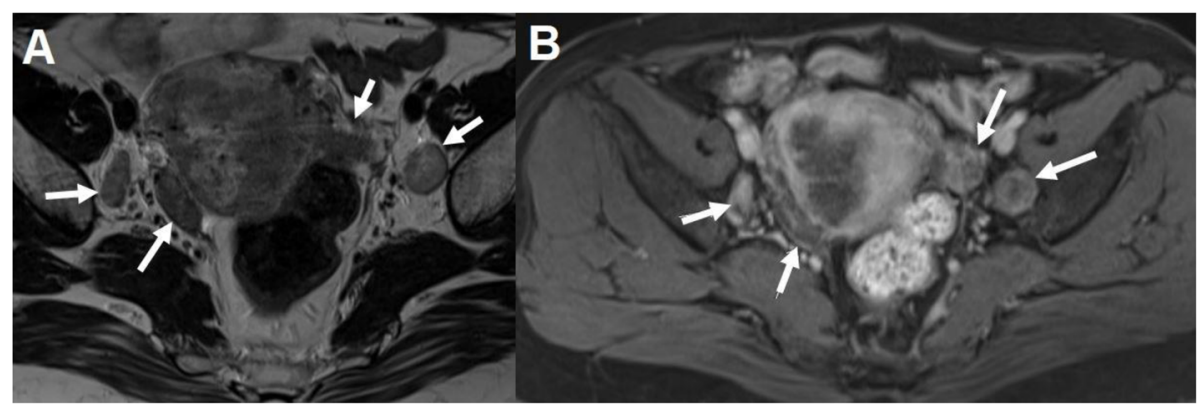

Fig. 4 Lymphadenopathy (arrows). A Axial T2W MRI, B gadolinium-enhanced T1-fat suppression sequence

moderate reliability (ICC 0.56, 95\% CI: $0.0004-0.756, \mathrm{P}$ value 2.03).

Lymphadenopathy is evaluated only by MRI in 27 (73.0\%) out of 37 patients. There are 21 patients (56.8\%) with pelvic lymphadenopathy and 6 patients with paraaortic lymphadenopathy (16.2\%). Three patients have both pelvic and para-aortic lymphadenopathy.

The number and percentage of vaginal invasion, parametrial invasion, pelvic sidewall invasion, hydronephrosis, adjacent organ invasion, and distant organ metastasis are summarized in Table 3.

\section{Discussion}

Although the correlation between overall clinical and MRI stagings by percent agreement in this study was moderate $(73.9 \%)$, the kappa coefficient $(K=0.000)$ showed a slight correlation. This might be due in part to the small sample size in this study. The previous study by Dhoot et al. showed a higher accuracy of $89.3 \%$ by MRI staging compared with $61.3 \%$ by clinical staging [4].

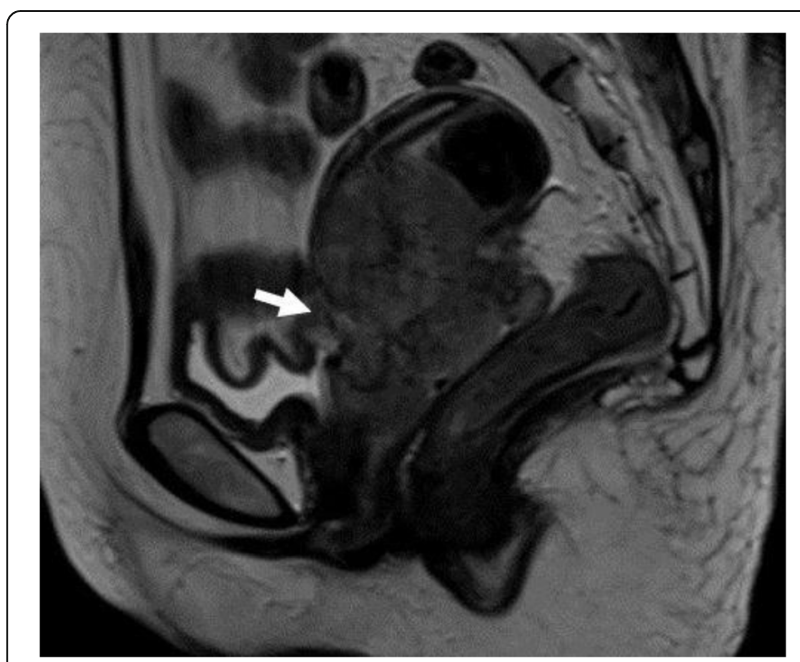

Fig. $5 \mathrm{~T} 2 \mathrm{~W}$ MRI sagittal view showed bladder invasion demonstrated as disruption of normal hypointense urinary walls without a mass protruding into the lumen (arrow)
Another study by Ho et al. (1992) showed the overall accuracy rate of MRI in staging of cervical cancer was $75 \%$, much higher than $55 \%$ by clinical staging $[6,7]$. Ozsarlak et al. demonstrated that the overall accuracy of cervical cancer staging by clinical examination and by MRI was 47 and $86 \%$, respectively [8]. Shirazi et al. showed $50 \%$ correlation between clinical and MRI stagings in stage IIIB patients (which is the main population in our study) [9]. According to the discrepancy between clinical and MRI stagings from previous studies, the slight correlation between clinical staging and MRI staging in cervical cancer in this study suggests the requirement of a large sample size study.

Other results such as vaginal invasion, pelvic sidewall invasion, adjacent pelvic organ invasion, and spreading to distant organs also showed moderate-to-strong correlation between clinical and MRI examinations by percent agreement (67.6 to $91.9 \%$ ), although the correlation between them was only slight by kappa or weighted kappa coefficient $\left(\mathrm{K}=0.000-0.128^{\mathrm{w}}\right)$. MRI sequences with other imaging modalities were used in the staging and follow the treatment of cervical cancer; i.e. relevant anatomy (including normal MRI appearance of the cervix, parametria, and pelvic ligaments), different stages of cervical cancer with prognostic and therapeutic implications [10].

For the parametrial invasion, both clinical and MRI examinations detected parametrial invasion in all 37 cases so that correlation analysis by both percent agreement and kappa coefficient was meaningless. One study reported that MRI has $74 \%$ and $93 \%$ sensitivity and specificity, respectively, to detect parametrial invasion [11]. Another study showed MRI accuracy in demonstrating parametrial involvement was $95 \%$, with $73 \%$ sensitivity, 96\% specificity, and $21-85 \%$ clinical staging accuracy [12]. According to the literature review by Thomeer et al. [13], MRI evaluation of parametrial invasion showed $84 \%$ pooled sensitivity (95\% CI $76-90)$ and $92 \%$ pooled specificity (95\% CI 90-95), whereas clinical examination showed $40 \%$ pooled sensitivity (95\% CI $25-$ 58 ) and $93 \%$ pooled specificity (95\% CI $83-89$ ). 


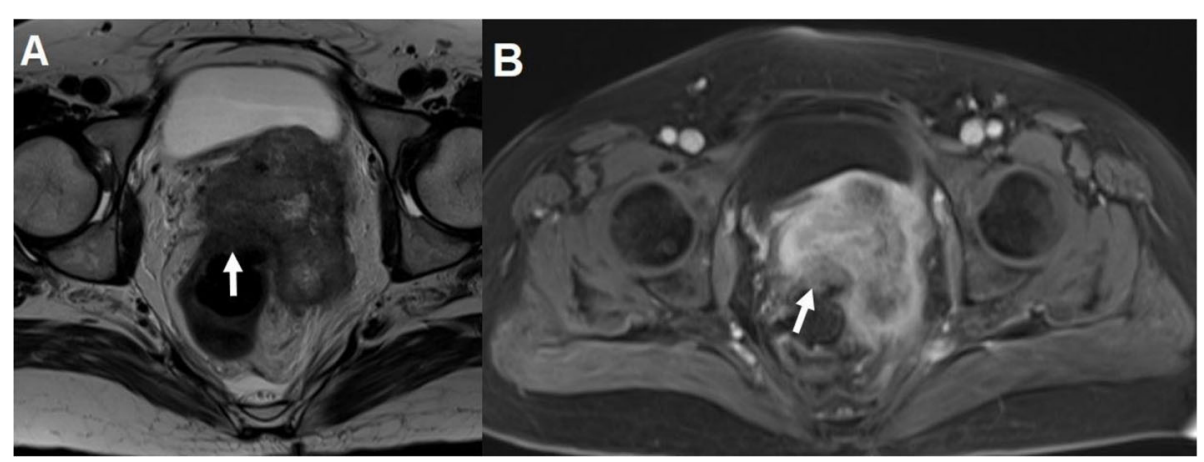

Fig. 6 Rectal invasion (arrows). A Axial T2WI showed disruption of their normal hypointense walls without a mass protruding into the lumen. B Axial gadolinium-enhanced T1-fat suppression sequences are helpful for confirming invasion

In this study, clinical and MRI evaluations for hydronephrosis showed a statistically significant correlation by kappa coefficient $(\mathrm{K}=0.749$, $\mathrm{P}$ value $<0.001)$. This may be because clinical examination evaluated hydronephrosis by intravenous pyelography. Our results corresponded well with the study by Chung et al. in that all 18 patients with hydronephrosis who were identified by intravenous pyelography were also recognized by MRI or CT [14].

\section{Advantages of pretreatment MRI}

Clinical examination can define dimension in an axial plane. Multiplanar MRI with higher spatial soft tissue resolution can define pelvic tumor extent, including more accurate assessment of tumor size, stromal invasion depth, and parametrial invasion [15].

In this study, 8 patients (21.6\%) had adjacent pelvic organ invasion by MRI, although the clinical examination cannot detect this finding. MRI has higher sensitivity to detect bladder invasion by early detection of bladder wall invasion, while clinical examination by cystoscopy needs to visualize intravesical tumor extension. Furthermore, the advantage of high spatial soft tissue resolution of MRI can also provide early detection of other adjacent pelvic organ invasions or distant organ metastases such as the rectum, colon, ovaries, etc.. This could potentially reduce staging costs and morbidity [16].

Table 1 Histology of patients' cancer (SCCA squamous cell carcinoma)

\begin{tabular}{ll}
\hline Histology & Amount \\
\hline SCCA & $7(18.92 \%)$ \\
SCCA (keratinizing) & $8(21.62 \%)$ \\
SCCA (large cell keratinizing) & $1(2.70 \%)$ \\
SCCA (large cell non-keratinizing) & $3(8.11 \%)$ \\
SCCA (non-keratinizing) & $17(45.95 \%)$ \\
Invasive SCCA (large cell non-keratinizing) & $1(2.70 \%)$ \\
\hline
\end{tabular}

In our study, the pathological staging was not compared with the clinical and MRI findings, which is a gold standard to show sensitivity or specificity of the tests, although pathological staging can provide how accurate the staging was by clinical and MRI examinations.

There is a selection bias of some certain staging (all the cervical cancer patients in this study are locally advanced disease or advanced disease) of cervical cancer because the patients who received pretreatment MRI in our hospital are mostly locally advanced disease (FIGO stage IIB or greater). Moreover, early staging patients were assessed by clinical FIGO staging and underwent surgical treatment, thus those patients were not evaluated by MRI for pretreatment planning. Therefore, our study has a small and insufficient number of patients to show a solid conclusion about the correlation between clinical and MRI stagings.

Also, because this study is a retrospective review, we cannot standardize MRI protocol and time interval

Table 2 Correlation of clinical staging and MRI staging in cervical cancer patients with pretreatment MRI $(n=37)$

\begin{tabular}{|c|c|c|c|c|}
\hline & & $\begin{array}{l}\text { Agreement } \\
\text { (\%) }\end{array}$ & $\begin{array}{l}\text { Kappa } \\
(95 \% \mathrm{Cl})\end{array}$ & $\begin{array}{l}Z(P \\
\text { value })\end{array}$ \\
\hline 1 & Vaginal invasion & 77.03 & $\begin{array}{l}0.128^{w} \\
(0.059 \\
0.259)\end{array}$ & $\begin{array}{l}1.11 \\
(0.133)\end{array}$ \\
\hline 2 & Parametrial invasion ${ }^{a}$ & - & - & - \\
\hline 3 & Pelvic side wall invasion & 67.57 & $\begin{array}{l}0.098 \\
(-0.083 \\
0.278)\end{array}$ & $\begin{array}{l}1.38 \\
(0.084)\end{array}$ \\
\hline 4 & $\begin{array}{l}\text { Hydronephrosis/ } \\
\text { nonfunctioning kidney }\end{array}$ & 91.89 & $\begin{array}{l}0.749 \\
(0.482 \\
1.000)\end{array}$ & $\begin{array}{l}4.57(< \\
0.001)^{*}\end{array}$ \\
\hline 5 & $\begin{array}{l}\text { Adjacent pelvic organ } \\
\text { invasion }^{\text {}}\end{array}$ & 78.38 & 0.000 & - \\
\hline 6 & Spread to distant organs ${ }^{b}$ & 91.89 & 0.000 & - \\
\hline 7 & Overall staging ${ }^{b}$ & 73.87 & $0.000^{w}$ & - \\
\hline
\end{tabular}


Table 3 Tumor invasions and distant metastases

\begin{tabular}{|c|c|c|}
\hline Sites & Clinical examination & MRI finding \\
\hline \multicolumn{3}{|l|}{ Vaginal invasion } \\
\hline No & $2(5.41 \%)$ & $0(0.00 \%)$ \\
\hline $2 / 3$ upper vagina & $29(78.38 \%)$ & $20(54.05 \%)$ \\
\hline $1 / 3$ lower vagina & $6(16.22 \%)$ & $17(45.95 \%)$ \\
\hline \multicolumn{3}{|l|}{ Parametrial invasion } \\
\hline No & $0(0.00 \%)$ & $0(0.00 \%)$ \\
\hline Yes & $37(100.00 \%)$ & $37(100.00 \%)$ \\
\hline \multicolumn{3}{|c|}{ Pelvic sidewall invasion } \\
\hline No & $1(2.70 \%)$ & $13(35.14 \%)$ \\
\hline Yes & $36(97.30 \%)$ & $24(64.86 \%)$ \\
\hline \multicolumn{3}{|l|}{ Hydronephrosis } \\
\hline No & $30(81.08 \%)$ & $29(78.38 \%)$ \\
\hline Yes & $7(18.92 \%)$ & $8(21.62 \%)$ \\
\hline \multicolumn{3}{|c|}{ Adjacent pelvic organ invasion } \\
\hline No & $37(100.00 \%)$ & $29(78.38 \%)$ \\
\hline Yes & $0(0.00 \%)$ & $8(21.62 \%)$ \\
\hline \multicolumn{3}{|c|}{ Distant organ metastases } \\
\hline No & 37 (100.00\%) & $34(91.89 \%)$ \\
\hline Yes & $0(0.00 \%)$ & 3 (8.11\%) \\
\hline
\end{tabular}

between clinical staging and pretreatment MRI examination, which might result in inaccurate comparison between clinical and MRI stagings.

Clinical examination limit to evaluate pelvic/para-aortic lymphadenopathy. Lymphadenopathy was evaluated by MRI in only 27 (73.0\%) out of 37 patients. Although the accuracy of MR imaging was fairly high in the detection of pelvic node metastasis from uterine cervical carcinoma, morphology and short-axis size (such as only round-shaped lymph node with less than $0.8 \mathrm{~cm}$ in short-axis size) of lymph nodes sometimes are equivocal to diagnose metastatic lymph node [17]. It should be aware that MRI will fail to detect metastasis in normal-size lymph nodes [18].

\section{Conclusion}

In patients with cervical cancer, pretreatment MRI provides higher spatial soft tissue resolution which can define pelvic tumor extent, including a more accurate assessment of tumor size (due to multiplanar evaluation), parametrial invasion, pelvic sidewall invasion, and adjacent pelvic organ invasion. This could potentially reduce staging morbidity by invasive investigation such as cystoscopy and proctoscopy.

\section{Abbreviations}

FIGO: International Federation of Gynecology and Obstetrics; CT: Computed tomography; MRI: Magnetic resonance imaging

\section{Acknowledgement}

We would like to acknowledge Professor Yukifumi Nawa who editing the manuscript via Publication Clinic KKU, Thailand.

\section{Availability of data and material}

All data and material in this study are available upon your request.

Authors' contributions

SN: methodology, validation, and writing review \& editing. CA: conceptualization, methodology, validation, resources, writing review \& editing, and project administration. WS: methodology, investigation, data curation, and writing original draft. KT: methodology, validation, and resources. AT: methodology, validation, and resources. The authors have read and approved the manuscript.

Funding

This research did not receive any specific grant from funding agencies in the public, commercial, or not-for-profit sectors.

\section{Declarations}

Ethics approval and consent to participate

This study was approved by the Khon Kaen University Ethics Committee for Human Research based on the Declaration of Helsinki and the ICH Good Clinical Practice Guidelines with reference number HE631559.

\section{Consent for publication}

Not applicable

\section{Competing interests}

The authors declare that they have no competing interests.

\section{Author details}

'Department of Radiology, Faculty of Medicine, Khon Kaen University, Khon Kaen, Thailand. ${ }^{2}$ Department of Obstetrics \& Gynecology, Faculty of Medicine, Khon Kaen University, Khon Kaen, Thailand.

Received: 21 April 2021 Accepted: 26 June 2021

Published online: 06 July 2021

\section{References}

1. Sung H, Ferlay J, Siegel RL, Laversanne M, Soerjomataram I, Jemal A, Bray F (2021) Global cancer statistics 2020: GLOBOCAN estimates of incidence and mortality worldwide for 36 cancers in 185 countries. CA Cancer I Clin https://doi.org/10.3322/caac21660

2. Valentini AL, Gui B, Micco M, Giuliani M, Rodolfino E, Ninivaggi V et al (2016) MRI anatomy of parametrial extension to better identify local pathways of disease spread in cervical cancer. Diagn Interv Radiol 22(4):319-325. https:// doi.org/10.5152/dir.2015.15282

3. Lee Sl, Atri M (2019) 2018 FlGO staging system for uterine cervical cancer: enter cross-sectional imaging. Radiology. 292(1):15-24. https://doi.org/1 $0.1148 /$ radiol.2019190088

4. Dhoot NM, Kumar V, Shinagare A, Kataki AC, Barmon D, Bhuyan U (2012) Evaluation of carcinoma cervix using magnetic resonance imaging: correlation with clinical FIGO staging and impact on management. J Med Imaging Radiat Oncol 56(1):58-65. https://doi.org/10.1111/j.1754-9485.2011. 02333.x

5. Nicolet V, Carignan L, Bourdon F, Prosmanne O (2000) MR imaging of cervical carcinoma: a practical staging approach. Radiographics. 20(6):15391549. https://doi.org/10.1148/radiographics.20.6.g00nv111539

6. Ho CM, Chien TY, Jeng CM, Tsang YM, Shih BY, Chang SC (1992) Staging of cervical cancer: comparison between magnetic resonance imaging, computed tomography and pelvic examination under anesthesia. J Formos Med Assoc 91(10):982-990

7. Mitchell DG, Snyder B, Coakley F, Reinhold C, Thomas G, Amendola M, Schwartz LH, Woodward P, Pannu H, Hricak H (2006) Early invasive cervical cancer: tumor delineation by magnetic resonance imaging, computed tomography, and clinical examination, verified by pathologic results, in the ACRIN 6651/GOG 183 Intergroup Study. J Clin Oncol 24(36):5687-5694. https://doi.org/10.1200/JCO.2006.07.4799 
8. Ozsarlak O, Tjalma W, Schepens E, Corthouts B, Beeck OB, Van ME et al (2003) The correlation of preoperative CT, MR imaging, and clinical staging (FIGO) with histopathology findings in primary cervical carcinoma. Eur Radiol 13(10):2338-2345. https://doi.org/10.1007/s00330-003-1928-2

9. Shirazi AS, Razi T, Cheraghi F, Rahim F, Ehsani S, Davoodi M (2014) Diagnostic accuracy of magnetic resonance imaging versus clinical staging in cervical cancer. Asian Pac J Cancer Prev 15(14):5729-5732. https://doi. org/10.7314/APJCP.2014.15.14.5729

10. Balcacer P, Shergill A, Litkouhi B (2019) MRI of cervical cancer with a surgical perspective: staging, prognostic implications and pitfalls. Abdom Radiol (NY) 44(7):2557-2571. https://doi.org/10.1007/s00261-019-01984-7

11. Bipat S, Glas AS, van der Velden J, Zwinderman AH, Bossuyt PM, Stoker J (2003) Computed tomography and magnetic resonance imaging in staging of uterine cervical carcinoma: a systematic review. Gynecol Oncol 91(1):5966. https://doi.org/10.1016/s0090-8258(03)00409-8

12. Kusmirek J, Robbins J, Allen H, Barroilhet L, Anderson B, Sadowski EA (2015) PET/CT and MRI in the imaging assessment of cervical cancer. Abdom Imaging 40(7):2486-2511. https://doi.org/10.1007/s00261-015-0363-6

13. Thomeer MG, Gerestein C, Spronk S, Doorn HC, Ham E, Hunink MG (2013) Clinical examination versus magnetic resonance imaging in the pretreatment staging of cervical carcinoma: systematic review and meta-analysis. Eur Radiol 23(7):2005-2018. https://doi.org/10.1007/s00330-013-2783-4

14. Chung H, Ahn HS, Kim YS, Lee EJ, Ryu HS, Chang KH, Kim SJ (2001) The value of cystoscopy and intravenous urography after magnetic resonance imaging or computed tomography in the staging of cervical carcinoma. Yonsei Med J 42(5):527-531. https://doi.org/10.3349/ymi.2001.42.5.527

15. Haldorsen IS, Lura N, Blaakaer J, Fischerova D, Werner HMJ (2019) What is the role of imaging at primary diagnostic work-up in uterine cervical cancer? Curr Oncol Rep 21(9):77. https://doi.org/10.1007/s11912-019-0824-0

16. Rockall AG, Ghosh S, Alexander-Sefre F, Babar S, Younis MT, Naz S et al (2006) Can MRI rule out bladder and rectal invasion in cervical cancer to help select patients for limited EUA? Gynecol Oncol 101(2):244-249. https:// doi.org/10.1016/j.ygyno.2005.10.012

17. Chen YB, Liao J, Xie R, Chen GL, Chen G (2011) Discrimination of metastatic from hyperplastic pelvic lymph nodes in patients with cervical cancer by diffusion-weighted magnetic resonance imaging. Abdom Imaging 36(1): 102-109. https://doi.org/10.1007/s00261-009-9590-z

18. Choi EK, Kim JK, Choi HJ, Park SH, Park BW, Kim N, Kim JS, Im KC, Cho G, Cho KS (2009) Node-by-node correlation between MR and PET/CT in patients with uterine cervical cancer: diffusion-weighted imaging versus size-based criteria on T2WI. Eur Radiol 19(8):2024-2032. https://doi.org/10.1 007/s00330-009-1350-5

\section{Publisher's Note}

Springer Nature remains neutral with regard to jurisdictional claims in published maps and institutional affiliations.

\section{Submit your manuscript to a SpringerOpen ${ }^{\circ}$ journal and benefit from:}

- Convenient online submission

- Rigorous peer review

- Open access: articles freely available online

- High visibility within the field

- Retaining the copyright to your article

Submit your next manuscript at $\boldsymbol{\nabla}$ springeropen.com 